\title{
APRENDENDO A OUVIR AS MULHERES KAWAIWETE-KAIABI: UM BREVE RELATO ETNOGRÁFICO
}

Learning to hear the kawaiwete-kaiabi women's voices: a brief ethnographic report

Jéssica Zaramella ${ }^{45}$

\section{Resumo:}

O presente texto trata de um relato etnográfico a respeito das narrativas e das perspectivas das mulheres kawaiwete-kaiabi sobre as maneiras cotidianas de fazer se roça. Tendo como objetivo evidenciar a importância de uma abordagem antropológica do cotidiano, como bem advogou a antropóloga Joanna Overing, buscarei destacar os elementos etnográficos que anunciam que a prática diária da roça não se trata apenas de uma atividade de subsistência, mas de um espaço no qual as mulheres kawaiwete-kaiabi se fazem, elaboram, inventam, criam e potencializam seus modos de se relacionar entre si, com o coletivo e com os seres.

Palavras-chave: Cotidiano; Mulheres indígenas; Kawaiwete-Kaiabi

\begin{abstract}
:
This text is an ethnographic description of the narratives and perspectives of kawaiwete-kaiabi women about the daily ways of doing horticulture. The purpose of this article is to highlight the importance of an anthropological approach to daily life, as anthropologist Joanna Overing has advocated, seeking to highlight the ethnographic elements that announce that the daily practice of horticulture is not just a subsistence activity, but a moment in which kawaiwete-kaiabi women make themselves and elaborate, invent, create and enhance their ways of relating to each other, to the collective and to beings.
\end{abstract}

Keywords: Daily life; Indigenous women; Kawaiwete-Kaiabi

\footnotetext{
${ }^{45}$ Mestranda em Antropologia Social pela Universidade de Brasília (UnB).
} 


\section{Apresentação}

Enquanto mulher e pesquisadora, tenho me dedicado a compreender e, sobretudo, a ouvir e aprender como outras mulheres concebem e elaboram suas vidas, suas comunidades, suas relações, seus mundos. Movida por esse interesse nas particularidades dos universos femininos, mais especificamente os das indígenas, aproximei-me das mulheres kawaiwete-kaiabi ${ }^{46}$, principalmente das residentes na aldeia Samaúma, localizada na região do Baixo Rio Xingu, dentro dos limites do Território Indígena do Xingu (TIX ${ }^{47}$ no Estado do Mato Grosso. Vale ressaltar que os Kawaiwete, outrora conhecidos pelo etnônimo Kaiabi, assumiram esta autodenominação no ano de 2005, após uma reunião das lideranças mais velhas no TIX, segundo me relatou Tariaiup Kayabi. Esta assembleia tinha como uma de suas pautas o desejo da etnia em se reafirmar como povo verdadeiro, tal como se denominavam no passado. Assim, Kawaiwete significa povo verdadeiro, guerreiro verdadeiro. De lá para cá, os pais têm buscado registrar seus filhos perante o Estado brasileiro como Kawaiwete.

Estas mulheres, com muito bom grado e paciência me receberam e têm compartilhado comigo desde o nosso primeiro contato uma infinidade de saberes sobre seu cotidiano, suas lutas políticas, suas comunidades. De igual modo, partilharam comigo suas concepções sobre a floresta, sobre as paisagens que as cercam com suas belezas e seus perigos. Contaram-me a respeito do rio pelo qual navegam, se banham, deixam de molho suas mandiocas e batatas e lavam suas roupas. Com muito entusiasmo me explicaram acerca das plantas das quais se alimentam, se enfeitam, se medicam e fazem seus tratamentos estéticos. E através das suas histórias sobre o dia-a-dia me contaram sobre os animais e seus modos de vida, sobre os espíritos, os donos, os encantados, os parentes, os brancos, o cosmos.

Dentre tantos modos para se acessar esses saberes femininos, foram as atividades diárias que se revelaram como o terreno profícuo para a investigação que tenho empreendido, uma vez que estas são expressões de elaborações muito refinadas de um modo de viver, estar e compreender um mundo. Minha vivência com estas mulheres retirou as práticas cotidianas do "fundo noturno da atividade social", como Michel de Certeau (1998) já nos provocava a fazer, e demonstrou que o interesse das Kawaiwete em realizá-las da melhor maneira possível se vincula àquilo que Joanna Overing (1999) identificou junto aos Piaroa do Rio Orinoco na Venezuela:

Os Piaroa atribuem a atividades que tendemos a ver como mera rotina (preparar uma refeição, limpar uma roça, trançar um cesto, alimentar um bebê) um significado bem maior, uma vez que seus principais interesses estão diretamente voltados para habilidades específicas essenciais à arte da vida diária. (OVERING, 1999: 81).

Fazer-se enquanto uma mulher ou um homem kawaiwete está intrinsicamente relacionado ao que se faz, como se faz e a qualidade com que se faz. O desleixo, as inabilidades técnicas, a falta dos saberes e o pouco interesse em conhecer os modos kawaiwete de se realizar uma atividade são vistos de forma negativa pela comu-

${ }^{46}$ Os Kawaiwete também são conhecidos na literatura etnográfica como Kaiabi/Kayabi (GRÜNBERG, 2004; NIMUENDAJÚ, 1948; OAKDALE, 2005; OLIVEIRA, 2010; RODRIGUES, 1964; TRAVASSOS, 1984) e pertencente à família linguística Tupi-guarani, como classificado por Aryon Dall'Igna Rodrigues (1964).

${ }^{47}$ Os Kawaiwete habitavam a região da Bacia do Rio Telles Pires. Com o avanço das frentes de extrativismo e a intensificação dos conflitos entre brancos e indígenas, iniciaram, a partir do final dos anos 40, o processo de migração, arquitetado e incentivado pelos irmãos Villas Boas, para o que se tornaria o atual TIX, sob a liderança de Prepori Kaiabi. Atualmente ocupam cinco porções de terras, todas localizadas no estado do Mato Grosso: 1) Território Indígena do Xingu (TIX), especificamente na região do baixo e médio rio Xingu; 2) Terra Indígena Apiaká-Kayabi, localizada no rio dos Peixes entre a Serra do Tombador e a Serra dos Caiabis; 3) Terra Indígena Batelão, também circunscrita no rio dos Peixes; 4) Terra Indígena Kayabi, na região de divisa entre o estado do Mato Grosso e o Pará, próxima a Serra do Cachimbo; 5) Terra Indígena Rio Arraias, perto da Serra Formosa (PIB, 2019). 
nidade. O status social de uma pessoa é reconhecido pela sua generosidade, pacificidade, bondade, prudência, cuidado e, também, pela destreza e zelo que possui e o empenho que emprega ao executar as tarefas cotidianas. Em consonância com Overing (2004), a vida diária é uma expressão do valor político e moral.

Contudo, isso não significa dizer que a inventividade e a criatividade se excluem dos trabalhos, pelo contrário, os Kawaiwete estão incansavelmente atualizando suas maneiras de fazer, ora adquirindo novas ferramentas, ora combinando suas técnicas com outras. O modo kawaiwete de se fazer as coisas é o da excelência, faz-se o melhor com o melhor que se tem à disposição. Em nossas conversas entre uma atividade e outra, as pessoas ao me explicarem como faziam as coisas, seja os objetos feitos artesanalmente (peneiras, abanadores, tipoia, redes, colares, pulseiras, brincos etc.), seja a preparação das refeições, o roçar, o plantar, o colher, o pescar, o caçar, ou a limpeza das casas etc., sempre ressaltavam as diferenças e as permanências nas maneiras de fazer.

Quando os indagava sobre essas alterações das técnicas, das ferramentas e dos materiais, eles buscavam exaltar suas habilidades de criação e inovação frente as adversidades, porém, não escondiam os incômodos sobre a escassez das matérias-primas que existem na região da Bacia do Rio Telles Pires, como é o caso das palhas usadas para fazer os telhados, as peneiras e os abanadores. Logo, não raras vezes apareciam em suas falam certo saudosismo no que toca estes recursos materiais. Lembro-me de Tuim Kayabi ${ }^{48}$, que enquanto entrelaçava as tramas de palha de um abanador me contava que havia encomendado o material dos parentes que moram na região do Baixo Telles Pires. A espera pelas palhas levou dois anos.

A escassez dos materiais utilizados pelos antigos ou a impossibilidade de realização de alguns detalhes das tarefas decorrentes das diferenças fito fisionômicas dos lugares pareciam molestá-los em algum sentido, porém faziam questão de ressaltar em suas falas que encontraram e continuam a encontrar formas variadas de prosseguir com os seus trabalhos cotidianos. Para tanto, o improviso está sempre colocado no dia-a-dia. A manutenção dos trabalhos diários é, em algum de seus aspectos dialogando com as proposições de Certeau (1998), uma forma de resistência cotidiana, que os faz garantir seu modo de viver frente as forças do confinamento e do avanço do mundo do branco.

As mudanças nas maneiras de fazer as atividades rotineiras não se dão apenas pela falta, mas também pelas vontades, desejos individuais e pelos intercâmbios de saberes. Agregar uma nova técnica que foi aprendida, passar a trabalhar com um novo material que se conseguiu com outro povo, otimizar uma dada etapa do processo dos trabalhos com as ferramentas obtidas pela troca com os brancos (agentes de saúde, técnicos de institutos que atuam na região, pesquisadores etc.) é muito comum e, quase sempre, desejado. Inúmeras vezes as mulheres ao verem algum objeto que eu havia levado comigo me perguntavam se eu queria fazer moitara, isto é, se eu queria trocar com elas. De igual modo estavam sempre atentas as minhas maneiras de fazer as coisas e me perguntavam sobre a minha rotina em minha casa. Para além da curiosidade de me conhecer melhor, que era evidente, pude perceber que elas estavam sempre em busca de outras formas de fazer as coisas que pudessem compor com as suas técnicas. O intercâmbio, como as mulheres kawaiwete costumam falar em português, a respeito das trocas de técnicas e saberes, é muito bem quisto.

Essas alterações nos modos como fazem algo não implicam o abandono das técnicas tradicionais ${ }^{49}$, elas acionam a criatividade, a inventividade, a imaginação dentro de um modo de relação. Ora, essas compo-

\footnotetext{
48 Tuim Kayabi, um velho kawaiwete extremamente respeitado por sua vida, generosidade, pacificidade e pelos conhecimentos que guardava da história dos Kawaiwete, infelizmente faleceu durante minha pesquisa de campo, em março de 2020.

${ }^{49}$ Adjetivo acionado pelos Kawaiwete em português para se dirigir as técnicas empregadas pelos antigos e transmitidas de uma geração para a outra.
} 
sições de operações que os homens e as mulheres fazem ao longo de seus dias ao executarem suas tarefas usuais desnudam o quão refinadas são estas práticas dentro da lógica em que operam seus modos de se relacionar com as coisas, com os seres e com o cosmos. Certeau (1998) afirma que as relações determinam seus próprios termos, isto é, possuem uma lógica operatória. Se tomarmos isso como premissa, é passível de verificação que é no cotidiano, nas maneiras de fazer, nas práticas diárias que se observa como as pessoas compõem operações, criam, elaboram e potencializam esses modos de relação.

Recordo-me dos fins de tarde na aldeia Samaúma. Logo que o sol começava a se pôr e a luz a se enfraquecer entre as casas, as mulheres se juntavam entre os corredores que desenhavam caminhos entre uma casa e outra. O banho de rio que refrescava o corpo do intenso calor do dia e o clima mais ameno do fim da tarde eram convidativos para estar fora de casa. Sentadas em seus pequenos e baixos bancos de madeira, fazendo seus colares de tucum e casco de jabuti, brincos e pulseiras de miçangas, conversavam comigo acerca do seu dia-a-dia.

Para toda tarefa havia uma história, ora sobre os tempos primordiais, ora sobra as suas próprias vidas, a ser contada que explicava o motivo pelo qual elas faziam as coisas de um modo específico. Essas histórias evidenciavam como elas se relacionavam com as coisas, com os parentes, com os seres, com a floresta, com o mundo. A maneira de fazer era evidentemente descrita como um modo de se relacionar. Foi então que identifiquei que mais do que me explicar como plantam, como colhem, como prepararam os alimentos, elas estavam me transmitindo o modo como elas se relacionavam com os cultivos, com a terra, com o dono dos cultivos e com a comida. Dito de outro modo, elas estavam me revelando suas concepções sobre o mundo.

Ao ouvir e comparar as narrativas das histórias, notei que alguns elementos que eram destacados pelas mulheres não apareciam nas narrativas dos homens e vice-versa. Assim, lembrei-me das provocações de Sandra Benites (2018) que dizem que as mulheres guarani nhandewa têm o seu próprio jeito de contar as histórias, ressaltando elementos que são importantes para elas nos modos como se relacionam e se fortalecem com o jeito coletivo guarani. Semelhantemente também fazem as mulheres kawaiwete ao narrarem as histórias da roça, dos piolhos, das muriçocas, dos jeitos de preparar os alimentos, entre outras, à sua própria maneira, evidenciando os elementos importantes para os seus modos de relação, para as suas habilidades de criar, inventar e fabricar o mundo. Nesse sentido, as práticas cotidianas se tornaram ainda mais um campo de meu interesse.

As Kawaiwete ao demonstrarem grande entusiasmo em me contar sobre essas práticas, estavam, na verdade, empolgadas por me mostrar suas percepções, suas leituras sobre a vida, sobre sua existência. Igualmente importante é o fato de que elas desejavam que eu aprendesse a todo custo as suas atividades. Queriam me ensinar a preparar o beiju, a torrar farinha, a fazer um colar de tucum, a identificar as diferentes variações das batatas e das mandiocas nas roças, a verificar se os amendoins cresciam bem. Logo, o que estavam me propondo era o experimentar na prática como é que elas se relacionavam com essas coisas. Não bastava me contar, era necessário que eu entendesse do que elas estavam falando, e para isso eu precisava me colocar em relação com as coisas.

À vista disso, tive a oportunidade de acompanhá-las em grande parte das suas atividades diárias. Mas foram as práticas hortícolas que mais me chamaram atenção. Para além de ser uma atividade central na garantia da subsistência das famílias e da comunidade, a roça é um espaço onde as mulheres se mostraram, pelo menos em minha estadia no campo, mais desinibidas e à vontade. Ao caminhar por entre uma roça e outra riam alto, faziam piadas umas com as outras, elogiavam as plantas, se lembravam das roças de outrora. Ficavam entusiasmadas quando as plantas cresciam bem e davam em demasiado, ao mesmo tempo que com grande pesar lamentavam os ataques dos animais. Durante nossas andanças pelas roças, as mulheres me contavam das relações que estabeleciam com suas avós, mães, filhas e cunhadas. Fazer roça com alguma de suas parentes é demonstrar apreço, é reafirmar os laços de parentesco. 
O conhecimento sobre as paisagens é minucioso. Enquanto eu andava apreensiva para não as perder de vista, sem saber ao certo onde pisar e no que podia ou não tocar, aquelas mulheres redesenhavam caminhos na mata fechada, indicavam antigas roças, coletavam frutas nativas e se entusiasmavam muito ao achar alguma matéria-prima para a fabricação de seus objetos. O seu conhecimento daqueles lugares é admirável e a relação entre paisagem e memória impressionante. Por cada lugar que passávamos, as paisagens ativavam nelas as memórias das gerações passadas, dos antigos. Ao lembrar de um parente, muitas vezes falecido, faziam questão de me contar como eram bonitos e grandes os cultivos plantados por ele. A memória afetiva de alguém estava sempre acompanhada do elogio das suas roças, da abundância de alimentos que a pessoa provia para a família e das suas maneiras de fazer as coisas.

"Será que nossas batatas ainda estão lá? Será que os animais, (queixada (porco do mato, Tayassu pecari), antas (Tapirus terrestres), cotias (Dasyprocta) etc.) atacaram nossas roças? Será que o inhame vai dar para mim? A sua roça está muito bonita, cunhada!". Essas são algumas das frases recorrentes que ouvi ao longo das conversas entre as mulheres no dia-a-dia, quer durante a fabricação de colares e pulseiras pela tarde, nas conversas ao pôr-do-sol, nas caminhadas até o rio, quer no estender das roupas. A atenção com suas plantas cultivadas e o cuidado das roças está constantemente nos diálogos estabelecidos entre estas mulheres.

Diante deste fato, encontrei nas técnicas de fazer roça um caminho para compreender em alguma medida as especificidades das percepções das mulheres kawaiwete sobre seu mundo, sobre as suas relações. Tendo isto como horizonte, inspirei-me nos estudos e nos debates desenvolvidos por antropólogas brasileiras na etnologia indígena que tocam as relações entre plantas e os humanos (LIMA, 2016; 2017; OLIVEIRA, 2006; 2012; 2016; SHIRATORI, 2018), bem como pelas proposições de Philippe Descola (2006) acerca dos Achuar do Equador. Debrucei-me, ainda, sobre bibliografias que se preocupam em compreender as especificidades das perspectivas femininas e suas elaborações no tocante aos seus mundos e suas comunidades (BENITES, 2018; MATOS, 2018; MCCALLUM, 1999; 2001; 2013; OVERING, 1999; 1991; VERON, 2018). Portanto, proponho-me neste texto a explorar, ainda que preliminarmente, em caráter ensaístico, uma narrativa feminina kawaiwete sobre o cotidiano do fazer a roça e as elaborações e percepções próprias que são acionadas nesta atividade.

Considerando que as atividades hortícolas são pertinentes tanto aos homens quanto às mulheres, $\mathrm{e}$ que a complementariedade do trabalho do casal é central para o bom desenvolvimento das roças, acredito ser necessário dizer que esta abordagem - a partir das narrativas femininas - não coloca as perspectivas masculinas e femininas como antagonistas ou mutualmente excludentes, como nós lembra Overing (1999: 83-84) ao afirmar que o antagonismo moral não é um fator distintivo das relações de gênero na Amazônia. Assim, as concepções masculinas e femininas se apresentam antes como visões conexas, narrativas múltiplas que conectam pontos de vistas diversos. Como fez Benites (2018), dedicar-me-ei sobre as versões que as mulheres contam das histórias e da vida.

Percebidos como exímios horticultores, tal qual demonstrou o antropólogo austríaco Georg Grünberg (2004), os Kawaiwete possuem grande diversidade de plantas cultivadas e suas atividades nas roças estão emaranhadas com o cotidiano e com a própria cosmologia. Assim, eles ainda crianças iniciam seu trato com estas atividades. Sendo uma atividade familiar, as crianças têm os primeiros contatos com as práticas observando, preferencialmente, o trabalho de seus pais e avós, podendo ser estes maternos ou paternos. Os meninos aprendem junto de seus parentes homens as atividades que lhes cabem - definição do local e do tamanho do terreno, a abertura da roça, a derrubada das árvores, a coivara e o preparo da terra, o arrancar das mandiocas e a preparação dos caminhos para o escoamento dos cultivos -, e as meninas recebem das parentes os ensinamentos sobre os modos de plantas, o manejo dos cultivos, a colheita e o armazenamento adequado das sementes.

É importante salientar que os espaços destinados ao plantio não são vivenciados e habitados apenas pelos Kawaiwete e pelas plantas por eles cultivadas, mas também por animais, insetos, vento, chuva, 
terra, sol, fogo e espíritos. Todos esses seres e donos de seres se relacionando estabelecem uma rede de interações mais que humanas, a qual requer das mulheres certos saberes que as colocam como agentes capazes de manejar um mundo.

Como demonstrou Lima (2017: 475), as plantas não são cultivadas em um ambiente vazio, logo fazer roça implica em um processo de coabitação envolvendo uma miríade de seres que afetam a dinâmica daqueles lugares. Para tanto, ao considerar a roça como um lugar de encontro de seres, de coabitação e de cooperação, é possível apontar que as maneiras de fazer roça, as habilidades de manejar essas atividades e de manter as relações acontecendo são fundamentais para a continuidade desta prática.

Estes saberes e técnicas estão atrelados às narrativas femininas que destacam certos elementos da história de origem das plantas cultivadas, a história de Kupeirup. Pelos caminhos de mato alto - elas reclamavam para mim que os homens haviam relaxado em sua obrigação de limpá-los - contavam-me a respeito desta história. Faziam questão de deixar claro a sua importância para elas e, consequentemente, da necessidade de se estabelecer uma relação positiva e harmoniosa com Kupeirup, o espírito dono dos cultivos. Por isso, segundo elas, o desleixo no trato com os cultivares é algo que pode ser muito perigoso, assim como é a negligência em cuidar dos caminhos até a roça.

Enquanto guardiãs dos saberes e conhecedoras das práticas hortícolas, as mulheres mais velhas transmitem as mais novas não apenas as destrezas técnicas que trabalhos requerem, mas percepções muito próprias, aquilo que com o passar dos anos, ao longo de suas vidas, conceberam. Conquanto, ainda que haja certa divisão sexual do trabalho e que, indubitavelmente, os homens possuam sua relevância na complementariedade das atividades e tenham outra percepção para evidenciar, tomarei o caminho da roça pelas falas das mulheres, buscando entendê-la como um espaço da elaboração e da criatividade feminina.

Isto posto, acredito que a apreciação e a investigação mais atentas das práticas diárias femininas, sejam quais forem, podem nos anunciar elementos próprios da elaboração das mulheres, as quais ainda têm muito a nós dizer. Logo, distante de uma abordagem que percebe a roça apenas como um espaço da produção da subsistência, meus esforços serão empregados em evidenciar os aspectos etnográficos, oriundos da vida ordinária, que ressaltam a importância de um olhar cuidadoso para as práticas femininas. Overing (1999) acentua a relevância de uma abordagem antropológica que leve à sério o cotidiano. Segundo a autora, as habilidades pessoais para a vida cotidiana em um universo de mundos múltiplos, repleto de agências, é o que permite a construção de uma vida diária bem-sucedida (OVERING, 1999). Assim, ao me debruçar sobre a vida cotidiana das mulheres kawaiwete na roça, acredito ser possível compreender como a percepção das práticas do dia-a-dia são elementares para a constituição de um ethos que se faz e se desdobra também a partir de um olhar feminino.

O conceito de ethos ao qual me refiro aqui, se vincula as considerações de Maurice Leenhardt (1997) a respeito das imbricações entre as histórias e a vida social. Em consonância com as proposições do autor, essas histórias expressam imagens muito vívidas da vida social, eles a orientam e promovem formas de relação. As instituições, as crenças, os hábitos alimentares, a organização social e as relações de parentesco etc., têm como fundamentação inúmeras histórias, que ao mesmo tempo em que organizam a vida, compõem um ethos, são atualizadas por essas realidades em constante transformação, pelo continuum das maneiras de fazer. Com base nisto, é possível afirmar que o modus vivendi não é de modo algum estático e completamente previsível, as mudanças que ocorrem, sejam por fatores endógenos ou exógenos, propiciam novos arranjos. Ora, as histórias são formulações muito complexas que ao mesmo tempo que trazem uma explicação para o mundo, em seu sentido mais amplo, e organizam a vida social, são capazes de aderir a novos elementos, produzindo novas formulações. E há que se dizer, sobre as suas formulações as mulheres kawaiwete estão em completa lucidez. 


\section{O cuidado e as maneiras de fazer}

Viver e experienciar as maneiras de fazer roça é rememorar no dia-a-dia o feito originário de Kupeirup. Em consonância com as falas das mulheres velhas, não há uma técnica, uma atividade hortícola se quer que se desempenhe sem que se remeta aos ensinamentos e as prescrições deixadas pelo espírito dono dos cultivos. O cuidado em seguir os mais simples preceitos são cruciais para que a roça aconteça, para que as plantas brotem, cresçam e alimentem os humanos. Logo, as meninas, desde muito novas, ouvem por várias vezes dos mais velhos a história de Kupeirup.

Havia um tempo em que os Kawaiwete não tinham roças e viviam da coleta de frutos e das caças. Os Kawaiwete tinham fome e não tinham comida de roça. Assim, Kupeirup que era uma mulher viúva, ao ver que os filhos não tinham o que comer, resolveu pedir a eles que abrissem uma grande roça. Os filhos, inquietos com o pedido da mãe, ficaram se questionando a respeito, afinal, não havia nada para plantar. Independentemente de não terem sementes, os dois filhos acabaram por fazer o que a mãe lhes pediu. Quando a mata foi derrubada e a roça estava pronta, Kupeirup os chamou para perto e disse a eles que a levassem para o centro da roça e ateassem fogo em seu corpo. Disse-lhes ainda que dos seus membros queimados brotaria para eles uma grande variedade de alimentos e que jamais teriam fome novamente. A princípio, os irmãos estranharam o pedido de sua mãe. Ficaram resistentes e tristes. Ao ver os filhos chateados, Kupeirup começou a consolá-los, dizendo que não os deixaria sozinhos e que se fizessem tudo corretamente ela estaria sempre por perto das roças e voltaria para eles.

Os dois irmãos ouviram então atentamente os ensinamentos e os conselhos de Kupeirup sobre os cuidados com o fogo, com a roça e com as plantas a serem cultivadas. Após receberem os saberes de sua mãe, os dois irmãos a levaram até o centro da roça, atearam fogo em seu corpo e foram para longe, para o lugar que a mãe lhes havia indicado anteriormente. Ao incendiar, o corpo de Kupeirup explodiu espalhando sementes de diferentes plantas por toda a roça. Os filhos, distantes dali, ficaram aguardando os sinais anunciados por sua mãe. Porém, um dos filhos não aguentou a curiosidade e, sem que seu irmão percebesse, foi para o local da roça espiar o que estava acontecendo. Ao ver o corpo de sua mãe explodir, ele se assustou e a sua mãe acabou caindo em um buraco e se transformou em uma paca. Logo depois disso, ele voltou para perto do irmão para esperar os sinais anunciados por sua mãe sem nada dizer. Quando passou por eles uma curica (Pyrilia caica), era sinal de que a roça estava quase boa. Tempos depois, um bando de curicas voou por cima de suas cabeças e, então, sabiam que a roça estava pronta e era chegado o momento de colher os alimentos que sua mãe os deixara. Ao chegarem na roça, viram muitos, muitos alimentos, uma abundância de cultivos.

Assim os milhos surgiram dos dentes de Kupeirup, o algodão e os fiapos do milho do cabelo, os amendoins da unha, as mandiocas da perna, as folhas de mandioca da mão, a cabaça da cabeça, o miolo de cabaça do miolo da Kupeirup, as pimentas dos dedos, a mandioca-doce das coxas, o líquido da mandioca-doce do leite do peito, o cará do pé, o feijão-fava da vulva e a batata do coração ${ }^{50}$.

Essa história me foi contada várias e várias vezes enquanto visitávamos as roças. Ao apontar um cultivo, as mulheres me diziam de qual parte do corpo de Kupeirup ele era originário. Sobre o trato com cada tipo de cultivar não era diferente, diziam-me que faziam assim porque as mulheres mais velhas lhes contavam que os antigos aprenderam assim com o espírito dono destas plantas. Não se pode negar que mudanças aconteceram, que novas ferramentas foram empregadas nos trabalhos hortícolas e que os atos de plantar, colher e manejar os cultivos sofreram alterações com o passar dos anos. Todavia, a lógica que ampara essas maneiras de fazer roça permanece presente. $\mathrm{O}$ cuidado, o respeito e certas etiquetas são primordiais para o sucesso das roças.

\footnotetext{
${ }^{50}$ Esta é uma apresentação breve e reduzida da história de Kupeirup, escrita a partir dos relatos das interlocutoras.
} 
A saber, as prescrições e etiquetas são transmitidas pelas velhas às mulheres mais novas diariamente e durante toda a vida. Desde pequenas, as meninas vão para as roças com sua mãe, suas avós e suas tias (maternas ou paternas). Aprendem a manusear corretamente as sementes, a plantar, o cuidado com cada tipo de cultivo, a colher, separar e armazenar as sementes, preparar os alimentos. São ensinadas também a como manejar os ânimos. É preciso que as mulheres saibam controlar seus sentimentos e humor, bem como motivar as plantas cultivadas. Ir para a área de plantação brava ou com raiva é algo a ser rechaçado. Além de ser uma demonstração pública de alguém não confiável, que é incapaz de manejar seus sentimentos, as ações desta mulher brava, raivosa, serão percebidas como e com hostilidade por Kupeirup e pelos cultivos, o que pode acarretar a perda das plantas e o fracasso da própria roça. Estar bem, alegre, feliz, é condição sine qua non para estar naquele lugar e para se relacionar com os seres que ali habitam. O cuidado e o zelo devem estar sempre presentes durante o trato com as plantas. Como sempre me alertavam, é preciso ser bondosa para com os cultivos.

Uma plantação bem-sucedida só acontece se essas plantas corresponderem a ação das mulheres. À vista disso, saber animar uma planta é conseguir estabelecer com ela uma relação de reciprocidade. Como bem demonstrou Cardoso (2017: 508), as mulheres ao terem uma percepção refinada sobre as plantas, são capazes de estabelecer relações de cuidado e reciprocidade com elas. Elas são detentoras de saberes muito minuciosos das especificidades de seus cultivos, logo são impressionantemente habilidosas em seu trato com as plantas.

A mulher planta e a semente dá para ela. A mulher cuida e a planta cresce grande e bonita. A mulher colhe e o cultivo alimenta os seus parentes. A mulher dá continuidade a descendência das plantas por ela cultivadas, e elas se dão e são dadas por Kupeirup em alimento à descendência da mulher. "A horticultora procede então a uma negociação dialética em que a mandioca se deixa comer pelos homens à condição que estes tratem de assegurar a continuidade de sua descendência" (DESCOLA, 2006: 122).

"Cresça, cresça grossa e forte como a minha coxa", são essas as palavras destinadas à mandioca-doce, contou-me Ryteé Kaiabi. Dizer isto enquanto se planta, é dizer à semente o que se espera dela. É motivá-la para que tenha um bom desenvolvimento. As plantas precisam ouvir as mulheres, precisam ser excitadas a brotar para elas. Por incontáveis vezes as mulheres me afirmavam a necessidade de se conversar com essas plantas. "Se você não falar nada, elas podem não dar, não crescer." Sendo assim, há uma expectativa nas primeiras vezes em que uma mulher planta sozinha. Mesmo que ela tenha sido cuidadosa em aprender os ensinamentos e os saberes transmitidos pelas velhas e conheça as técnicas de manejo, não se tem a certeza de as plantas a aceitarão. Ora, não se sabe ao certo se alguma planta dará para ela.

A aceitação de uma mulher por um ou mais cultivos é vista por todos. A planta cultivada brota bonita, grande e saborosa, o que confere certo prestígio entre seus pares àquela que a plantou. A rejeição é igualmente notada, o cultivo plantado não dá, ou quando dá, nasce disforme, pequeno, feio e insosso. Diante disso, entende-se que a relação entre elas não foi exitosa, dado que uma parte - a planta - não correspondeu aos tratos da outra - a mulher. Como dizem os Kawaiwete: "a planta não deu para você".

O trato com os cultivares não é, portanto, unilateral. O cuidado da mulher em estimular o seu crescimento através das palavras durante o plantio - e só se fala neste momento com as plantas - e a sua maneira de plantar precisa ser antes aceito pela planta. Esta última deve se deixar ser plantada e cultivada, caso contrário, o cuidado será ineficaz. Dito isto, há uma negociação entre as mulheres e os cultivares que é intermediada por Kupeirup. Se as primeiras são respeitosas, tratam bem as sementes, cuidam dos corpos das plantas e as protegem dos animais predadores e das pragas, Kupeirup se alegrará e seus cultivos corresponderão sendo alimentos bons e saudáveis para a comunidade. Caso contrário, o espírito dono das plantas deixará os Kawaiwete sem alimentos, os cultivos não darão para eles. "Quando fazemos alguma coisa errada, ela faz mal pra gente, não dá pra gente." 
O cuidar bem das plantas é também agradar Kupeirup. O espírito dono dos cultivos está sempre atento as ações das Kawaiwete na roça e fora dela. As mulheres devem se preocupar em cuidar e armazenar muito bem as sementes. Em hipótese alguma se permite brincar com elas. Enquanto guardiãs das sementes, são elas que possuem os saberes necessários e a maneira de fazer adequada para manter junto da comunidade cada espécie de cultivo.

No preparo dos alimentos, as velhas advertem sempre em que há alguma forma de desperdício. Jogar fora partes das plantas é tratá-las com desdém, o que pode irritar Kupeirup. Comer milho ou amendoim jogando-os para o alto é considerado uma ofensa ao que se come, bem como ao espírito da roça. É quase como dizer: "não preciso disso para viver". Logo, ao jogar o amendoim e o milho para o alto, corre-se o risco de Kupeirup pegá-los e nunca mais devolvê-los. Ademais, quando se trata dos cultivos, as mulheres, especialmente as mais velhas, estão em contínuo estado de vigilância, cuidando para que ninguém da comunidade haja desrespeitosa ou descuidadamente com eles. A possibilidade de vingança de Kupeirup pode custar muito aos Kawaiwete.

Diferentemente do que se possa imaginar, o ambiente em que se planta está longe de ser um espaço plenamente harmônico. $\mathrm{O}$ risco das retaliações e da vingança estão sempre postos, por isso o saber se relacionar com as plantas e com Kupeirup é um desafio vivenciado cotidianamente pelas mulheres. A reciprocidade positiva ou negativa é o que constitui a ambivalência da roça. Ora, um espaço próximo às malocas, desenhado e projetado pelos homens, cuidado e aprimorado pelas mulheres, vivenciado em comunidade e manejado pelos humanos e pelos demais seres, apresenta nuances perigosíssimas quando se compreende que cada ação humana é, na verdade, uma negociação com os seres que ali habitam. Logo, como em toda negociação os desarranjos e descompassos são uma possibilidade, cabe aos Kawaiwete, mais especificamente as mulheres, cuidarem para que a reciprocidade positiva se realize.

São elas, portanto, quem mantêm as relações acontecendo. Mais do que isso, a perspectiva feminina da roça assevera o quão perigoso pode ser estar naquele lugar. Um erro, um descuido, um descontrole da raiva, e tudo pode acabar. É por isso que a lógica do cuidado tão exercida pelas mulheres se faz fundamental para a continuidade das roças. Cuidar da alimentação, cuidar das roças, cuidar das plantas, das crianças, dos homens, das outras mulheres, dos comportamentos, dos ânimos, é cuidar da própria existência da comunidade. E este cuidado, explicita certas maneiras de fazer as coisas e formas de relação que são transmitidas de mulheres para mulheres a partir de suas narrativas sobre as histórias, sobre a vida. Conhecer as maneiras de fazer e saber contar histórias é um saber a respeito do modo kawaiwete de se relacionar com os seres, com as coisas e com o mundo. É saber manejar as potencialidades positivas e negativas destas relações e explorar suas virtudes.

Sendo assim, no ordinário, as maneiras de fazer roça e de cuidado das mulheres são o que mantêm a vida da comunidade acontecendo, afinal os alimentos da roça preparados por essas mulheres são imprescindíveis para fazer dos Kawaiwete o que são.

Oliveira (2016) aponta que a mulher horticultora não garante apenas a subsistência de sua família, mas fundamenta a vida social oferecendo aos seus parentes uma alimentação adequada. Assim o ato de alimentar parentes implica no estreitamento dos laços sociais bem como na construção dos corpos das pessoas. Assim, se observarmos a relação entre as mulheres mais velhas e as mais novas, podemos verificar, como nos inspira Lotierzo (2018: 73), que as últimas ao serem instruídas, cuidadas, ao recebem conselhos e serem alimentadas pelas primeiras, têm o seu corpo preparado para um dia poder ensinar, cuidar, alimentar.

\section{A figura de uma mulher confiável e respeitada}

Ser reconhecida como uma boa mulher pelos Kawaiwete está rigorosamente vinculado ao manejo dos ânimos, as atitudes virtuosas (bondade, pacificidade, prudência e cuidado) e com as atividades desempenhadas 
na roça e as demais atribuições ordinárias. Para se fazer uma mulher respeitada e confiável é preciso estar junto das suas parentes nas atividades cotidianas e conhecer os saberes femininos. Ouvir as mulheres velhas, aprender a sabedoria das suas avós, da sua mãe e das suas tias é condição para que a menina se faça e seja feita por essas outras mulheres uma boa mulher kawaiwete.

Durante meus dias em Samaúma, uma jovem de 18 anos, Amanda Kayabi ${ }^{51}$, foi minha tradutora, companheira e amiga. Foi ela quem me apresentou à todas as mulheres da aldeia, que me ensinou a armar minha rede, a fazer fogo, quem me acompanhava nos banhos de rio e trazia alimentos para mim. Nós passávamos horas conversando e nestas prosas diárias aprendi muito sobre o que se espera de uma mulher kawaiwete. Amanda me contava da sua vida, de quando começou a aprender a fazer tipoia, rede, a produzir pulseiras, colares, brincos. Como foi quando passou a acompanhar sua mãe e tia materna na roça e a aprender a práticas culinárias. Ela é uma jovem muito admirada em sua aldeia e a quem se confere várias responsabilidades, como a recepção de pesquisadores e o cuidado da casa de sementes ${ }^{52}$. Ao acompanhá-la em seu dia-a-dia, pude ver que sua mãe não lhe pedia nada, ela sabia o que devia fazer. Sempre presente com as demais mulheres, ela passava o dia alternando suas atividades em cuidar da casa de sementes, fazer pulseiras, colares, tipoias, preparar as refeições, preparar a goma para o beiju e ir com sua mãe e sua tia materna até a sua roça de mandioca.

Percebi que as mulheres mais velhas não precisavam chamá-la para fazer atividade alguma, logo que começava uma dada movimentação, Amanda dirigia-se para perto das demais mulheres e dava início aos seus trabalhos. Certa vez, ela me disse que a mãe começa a chamar a filha ainda criança para fazer as atividades, se a filha a acompanha, aprenderá as maneiras de fazer as coisas, mas se a filha não quiser a mãe não insistirá. Conforme o que ela me relatou, o aprendizado depende de cada um e a autonomia das pessoas, ainda que sejam crianças, é respeitada pelas demais. Porém há prejuízos em não saber realizar as atividades. Além de não conseguir produzir o que é necessário para a vida, há prejuízos sociais. Uma pessoa que não sabe as maneiras de fazer e não está continuamente trabalhando é vista como alguém não confiável.

Overing (1999) relatou em relação aos Piaroa:

A ênfase que os Piaroa põem no cotidiano e nas atividades diárias não é trivial, mas sim o produto de uma poderosa filosofia social, altamente igualitária. Este é um povo, tipicamente amazônico, que recusa abertamente a ideia de regra social e, no entanto, valoriza fortemente a socialidade, seus próprios costumes e a mutualidade dos laços comunitários - ao mesmo tempo que dá provas de um forte apreço pela autonomia pessoal. (OVERING, 1999: 85)..

Mostrar para a comunidade que se sabe as maneiras de fazer e que se conhece as histórias contadas pelos mais velhos é sinal de virtude e confiança. Há uma estreita relação entre a execução zelosa das atividades diárias, conhecimentos dos saberes e confiança. Overing (1999) afirma que a relação de confiança se dá entre os membros de uma comunidade a partir da ênfase no informal e no íntimo. A autonomia das pessoas é priorizada e os laços de confiança são criados antes pela disposição pessoal em participar ativamente da vida comunitária e coletiva do que por obediência a regras. "[...] Aqui, o relacionamento de confiança apropriado pertence mais ou menos ao domínio da intimidade, em oposição ao domínio da lei

\footnotetext{
${ }^{51}$ A Amanda possui outros nomes na língua, mas era chamada por todos na comunidade apenas pelo seu nome em português

${ }^{52} \mathrm{O}$ projeto da Casa de Sementes está vinculado à Rede de Sementes do Xingu, que é uma iniciativa que promove a troca e a encomenda de sementes nativas das regiões do Rio Xingu e outras áreas a fim de promover a recuperação de áreas desmatadas. Essas casas construídas nas aldeias são locais de armazenamentos das sementes, a partir das quais se faz o balanço das sementes coletadas em determinadas aldeias e, posteriormente, são enviadas a sede da Rede. Para mais informações consultar: https://www.sementesdoxingu.org.br..
} 
ou do contrato coercitivos [...]" (OVERING, 1999: 82). Em concordância com isto, uma menina kawaiwete jamais será obrigada a realizar uma tarefa, mas os benefícios sociais de se fazer e os prejuízos de não fazer são realidades com as quais as terá que lidar. Para tanto, pude observar que Amanda estava sempre participando de uma atividade, trabalhava incansavelmente e buscava sempre a excelência em suas tarefas. Por vezes, ouvi elogios de outras mulheres sobre as suas tipoias, redes, colares e pulseiras, sobre como ela conseguia carregar uma grande bacia de mandiocas sem deixar cair.

Em nossas idas a roça, ela trabalhava muito. Colhia as mandiocas, ajudava a separá-las, enchia as bacias, carregava estas mesmas bacias de metal pesadas em sua cabeça várias e várias vezes até conseguir levar toda a colheita para a aldeia e ao chegar próximo à beira do rio, conjuntamente com as demais mulheres, colocava as mandiocas de molho. Sua disposição em participar coletivamente das atividades femininas conferiam a ela certo grau de confiança perante as demais mulheres, ainda que fosse muito jovem.

$\mathrm{O}$ aprendizado das meninas e mulheres mais novas se dá, à vista disso, de modo autônomo. Enquanto as mulheres mais velhas executam as atividades hortícolas, cabe as mais novas buscar a instrução e a orientação destas mulheres, seja para a aquisição das habilidades técnicas seja para aprender a manejar suas emoções - qualidade muito apreciada pelos Kawaiwete. Saber controlar o ânimo e as suas emoções é uma característica importante para ser uma boa horticultora. Por isso, o trabalho na roça não se restringe a aprender um conhecimento técnico no trato com as plantas, mas a se construir como uma mulher sabida, que possui a sabedoria necessária para empregar as técnicas, bem como manejar seus próprios ânimos, fazendo-se capaz de lidar com as alteridades presentes neste espaço e de se relacionarem com as demais.

A aquisição de habilidades técnicas nos membros do corpo, e sobretudo nas mãos, perpassa pela observação das maneiras de fazer. Entre as mulheres kawaiwete o aprendizado das técnicas de manejo dos cultivos também se dá a partir da observação cuidadosa dos movimentos das mãos das mais velhas. O olhar esperto e a atenção à destreza dos movimentos das mãos das velhas são fundamentais para um bom aprendizado. Além de observar, é preciso fazer. Segundo as Kawaiwete, elas aprendem na prática, aprendem fazendo. O corpo de uma mulher horticultora se faz, portanto, durante as atividades na roça. O conhecimento proveniente da observação e da repetição dos movimentos se apresenta no corpo das meninas, seja no modo de empregar a força das mãos, no cavar com o facão, no agachar para procurar as batatas, o inhame, o cará, as mandiocas. Essas habilidades que vão se tornando em destrezas, e ao se atrelarem as inovações, as invenções, aos experimentos que elas vão fazendo, testando aqui e acolá um outro jeito de fazer, uma nova ferramenta, vão compondo outros arranjos e outras operações com as maneiras de fazer conhecidas. Essas novas elaborações quando bem-sucedidas dão as mulheres credibilidade frente as demais, e ela passa a compartilhar com as outras seu jeito de fazer que fortalece a maneira coletiva de fazer.

Quando fomos visitar os parentes da aldeia Kwarujá, Wisió Kayabi, a primeira cacica kawaiwete e uma figura de muita confiança e respeito, me disse: "eu vou fazendo do meu jeito. A gente aprende com a nossa mãe, com as nossas avós a maneira de fazer as coisas e a gente vai fazendo em cima disso". Assim sendo, ao longo do seu desenvolvimento, as mulheres vão se tornando cada vez mais "sabidas", como me diziam elas, e com mãos mais habilidosas, sobretudo com o avançar da idade. As mulheres kawaiwete dizem que há sempre que se aprender com as mulheres velhas. À vista disso, a mulher mais velha que é considerada uma exímia horticultora, é alguém a quem se deve muito respeito e em quem se deposita muita confiança. Ela é quem é capaz de manejar os ânimos, o próprio e o das plantas. O seu corpo é habilidoso o suficiente para desempenhar os trabalhos. É uma mulher que foi aceita por uma ou mais plantas, aquela que conseguiu estabelecer uma relação de reciprocidade com as alteridades presentes neste espaço, de modo a garantir a continuidade da sua descendência a partir da aquisição satisfatória da subsistência. É, também, aquela que consegue trazer para perto de si outras mulheres. Seus saberes acabam sendo deseja- 
dos pelas demais e o compartilhar deste acentua ainda mais os laços com as parentes, com o coletivo. Mais do que acumular saberes é preciso compartilhá-los.

Essas mulheres mais velhas, em quem se reconhece uma mulher respeitada e confiável, são aquelas que têm espaços para falar para a comunidade. Suas vidas de trabalho e de dedicação ao cuidado de si e dos demais dão a elas a legitimidade necessária para dar conselhos, para conduzir discussões. Tornam-se exemplos, figuras admiradas, chegando a posições de lideranças.

\section{Considerações finais}

Tendo em conta que a roça é uma atividade que se desenvolve atrelada ao miúdo da vida, ao cotidiano, é possível apreender que as mulheres kawaiwete ao executarem as suas atividades elaboram um mundo de relações que envolve os parentes e alteridades outras. Praticar as maneiras de fazer a roça é, portanto, saber se relacionar com uma diversidade de seres que afetam a vida da comunidade, como é o caso dos cultivos e de Kupeirup. É saber as regras de etiqueta social, a lógica das relações. Conhecer as prescrições, manejar os ânimos, as habilidades fundamentais é ser kawaiwete. Assim, acredito que as elaborações femininas provenientes da vida na roça, como a respeito das demais práticas cotidianas, acabam por desmanchar a ideia do ordinário como algo corriqueiro e banal, especialmente, se observados a partir das histórias narradas por elas e pelas informações que as mulheres nos relatam acerca da vida rotineira. "Há uma rica etnografia que é essencial, com as pessoas conversando entre si e compartilhando experiências. As pessoas podem ser realmente interessantes, com verrugas e tudo [...]." (OVERING, 2004: 12). Parece-me urgente que nos voltemos para o ordinário e, mais, que aprendamos a ouvir as mulheres.

\section{Referências}

BENITES, Sandra. 2018. Viver na língua Guarani Nhandewa (mulher falando). Rio de Janeiro-RJ: Dissertação de mestrado em Antropologia Social, Museu Nacional/Universidade Federal do Rio de Janeiro.

CARDOSO, Thiago Mota. 2017. "Entrelaçando mulheres e plantas. Ensaio fotoetnográfico do mundo da roça no Rio Negro”. Amazônia - Revista de Antropologia, v. 9, n. 1: 504-578.

CERTEAU, Michel de. 1998. A invenção do cotidiano. 3.ed. Petrópolis: Editora Vozes.

DESCOLA, Philippe. 2006. As lanças do crepúsculo. São Paulo: Cosac Naify.

GRÜNBERG, Georg. 2004. Os Kaiabi do Brasil Central. História e etnografia. São Paulo: Instituto Socioambiental.

LEENHARDT, Maurice. 1997. Do Kamo: la persona y el mito en el mundo melanesio. Barcelona: Paidós.

LIMA, Ana Gabriela Morim. 2017. "A cultura da batata-doce: cultivo, parentesco e ritual entre os Krahô". Mana, v. 23, n. 2: 455-490.

2016. "Brotou batata para mim": cultivo, gênero e ritual entre os Krahô (TO, Brasil). Rio de Janeiro-RJ: Tese de doutorado em Antropologia Social, Universidade Federal do Rio de Janeiro.

LOTIERZO, Tatiana. 2018. "Dos corpos, a terra: notas sobra a criatividade o trabalho de Rosa Tisoy". Campos, v. 19, n. 1: 59-85.

MATOS, Beatriz de Almeida. 2018. Povo onça, povo larva: animais e plantas na constituição da pessoa, diferenciação de gênero e parentesco matses. Revista de Antropologia, v. 61 n. 3: 95-128. 
MCCALLUM, Cecília. 1999. "Aquisição de gênero e habilidades produtivas: o caso kaxinawá". Revista Estudos Feministas, v. 7, n. 1 e 2: 157-175.

2001. How real people are made. Gender and sociality in Amazonia. Oxford-UK: Berg.

2013. "Intimidade com estranhos: uma perspectiva kaxinawá sobre a confiança e a construção de pessoas na Amazônia”. Mana, v. 19, n. 1: 123-155.

NIMUENDAJÚ, Curt. 1948. “The Cayabi, Tapanyuna, and Apiaca”. In: STEWARD, Julian H. (ed.). Handbook of South American indians. v. 3. Washington-USA: Smithsonian Institution. p.307-320.

OAKDALE, Suzanne. 2005. I foresse my life. The ritual performance of autobiography in an Amazonian Community. Nebraska-USA: University of Nebraska Press.

OLIVEIRA, Frederico César Barbosa de. 2010. Quando resistir é habitar: lutas pela afirmação territorial dos Kaiabi no Baixo Teles Pires. Brasília-DF: Tese de doutorado em Antropologia Social, Universidade de Brasília.

OLIVEIRA, Joana Cabral de. 2006. Classificações em cena. Algumas formas de classificação das plantas cultivadas pelos Wajãpi do Amapari. São Paulo-SP: Dissertação de mestrado em Antropologia Social, Universidade de São Paulo.

. 2012. Entre plantas e palavras. Modos de constituição de saberes entre os Wajãpi (AP). São Paulo-SP: Tese de doutorado em Antropologia Social, Universidade de São Paulo.

. 2016. "Mundos de roças e florestas". Boletim do Museu Paraense Emílio Goeldi. Ciências Humanas, v. 11, n. 11: 115-131.

OVERING, Joanna. 1991. "A estética da produção: o senso de comunidade entre os Cubeo e os Piaroa". Revista de Antropologia, n. 34: 7-33.

1999. "Elogio do cotidiano: a confiança e a arte da vida social em uma comunidade amazônica". Mana, v. 5, n. 1: 81-107.

2004. "A reação contra a descolonização da intelectualidade". Ilha - Revista de Antropologia, v. 6, n. 1 e 2: 5-27.

PIB - Povos indígenas no Brasil. Resultados sobre a etnia Kaiabi. Disponível em: $<$ https://pib.socioambiental.org/pt/Povo:Kaiabi>. Acesso em: 22 set. 2019.

RODRIGUES, Aryon Dall'lgna. 1964. "A classificação do tronco linguístico Tupí". Revista de Antropologia, v. 12, n. 1 e 2: 99-104.

SHIRATORI, Karen. 2018. O olhar envenenado: da metafísica vegetal jamamadi (Médio Purus, AM). Rio de Janeiro-RJ: Tese de doutorado em Antropologia Social), Museu Nacional/Universidade Federal do Rio de Janeiro.

TRAVASSOS, Elizabeth. 1984. Xamanismo e música entre os Kaiabi. Rio de Janeiro-RJ: Dissertação de mestrado em Antropologia Social, Museu Nacional/Universidade Federal do Rio de Janeiro.

VERON, Valdelice. 2018. Tekombo’e Kunhakoty: modo de viver da mulher kaiowá. Brasília-DF: Dissertação de mestrado em Sustentabilidade junto a Povos e Territórios Tradicionais, Universidade de Brasília. 
